\title{
USING MULTIMEDIA IN DOCUMENTING AND ARCHIVING THE ISLAMIC ARCHITECTURAL HERITAGE OF THE HOLY MOSQUE AREA IN MAKKAH CITY, SAUDI ARABIA
}

\author{
REEM F. ALSABBAN ${ }^{1} \&$ MARWAN A. FATANI ${ }^{2}$ \\ ${ }^{1}$ King Abdulaziz University, Saudi Arabia \\ ${ }^{2}$ Holy Makkah Municipality, Saudi Arabia
}

\begin{abstract}
This paper aims to analyse and document the architectural heritage of the Holy Mosque in Makkah, Saudi Arabia (Al-Masjid Al-Haram) and its surrounding area. It focuses on the use of multimedia videos, photographic pictures and virtual reality technology in documenting the architectural heritage of the Grand Mosque area in the period following the new expansion and renovation of the Holy Mosque (within the last ten years) and compares it to the pre-expansion period. Muslims gave special care to building the Holy Mosque as they consider it the holiest place on earth. They did all they could to take care of it and develop the surrounding architecture to serve the large number of pilgrims and worshippers who visit the Mosque each day. The last ten years witnessed huge expansions to the Holy Mosque, several applications of modern design solutions, and developments in buildings, which led to the dispense of some of the historical architectural elements that have been decorating the Holy Mosque for decades. To preserve these decorations, and to shed light on the beauty of the current developed designs, they need to be analysed using photographic pictures, and documented using virtual reality technology, allowing interested researchers to study them in the future. The team of researchers for this paper consists of professional photographers, architects and interior designers. The research uses historic descriptive and analytical methods to achieve its aim.

Keywords: Islamic architecture, Islamic heritage, the Holy Mosque in Makkah, historical architectural elements, Al-Masjid Al-Haram, architectural analysis, multimedia documentation, historical descriptive method, virtual reality, architecture documentation.
\end{abstract}

\section{INTRODUCTION}

During the past ten years, the Haram area of the Islamic Holy City, Makkah, in Saudi Arabia has witnessed huge expansions in line with the steady increase in the number of visitors and pilgrims to this honorable spot of land. In turn, these expansions have led to the removal of many historic buildings surrounding the Haram area to facilitate the execution of this project, which resulted in a mass change of the geographic and historical composition of this area. In view of the historical value of these buildings, information about them should be archived in an appropriate way so that it will be accessible to researchers and scholars. Architectural documentation of archaeological sites and buildings is one of the most important means of preserving heritage. This archiving process could be done using the latest technological methods; especially, ones which encourage immersion and interactivity like Augmented Reality (AR) and Virtual Reality (VR).

The current paper documents only the first phase of a multi-phase project aiming at the preservation of the Haram area architectural heritage using modern technology. It is part of a national research agenda, which will undoubtedly help in digitizing information about Islamic as well as national Saudi heritage in this Holy area. The objective of this initial implementation of the architectural documentation process is to develop a virtual reality multimedia, guided tour which documents a historical building in the Haram area. 
This study is particularly concerned with the details of interior architecture that are useful to the researchers in the field of interior design, which have not been paid enough attention perhaps because of the difficulty of visualizing life in the interior spaces in those periods and the scarcity of documented references. However, with the help of old photographs, artwork, and field visits to still existing buildings, including residential or administrative buildings or museums containing personal possessions, it is possible to re-depict the period in a way that describes the design details of the decorations and elements that will rejuvenate the life of these beautiful buildings in the past.

The process of architectural documentation is one of the first processes to preserve historical and archaeological buildings, and with the advent of the digital revolution and the emergence of advanced technologies, it becomes even more feasible to perform architectural documentation.

To achieve the objective of this paper, it is divided into four sections. The first section reviews research done about the use of modern technology in architectural documentation. The second section deals with the expansion of the Haram area and reviews the spaces, buildings and areas that were removed and re-used as expansion spaces for the expansion project. The third section focuses on prevalent methods used in archiving historic buildings. The fourth section demonstrates the results of the pilot carried out on one historic building in which modern methods of architectural archiving were used and multimedia resources were created.

\section{LITERATURE REVIEW}

Several studies have discussed modern methods of architectural documentation using advanced technologies, which indicates the rising interest in multimedia visualizations in this domain of research. Gaafer [1] developed a virtual 3D model using photo-modeling techniques to document the Islamic architectural heritage in Jerusalem, Palestine. They used the available pictures in previous literature and other media references because of the high security restrictions in the area to document many features in al Aqsa Mosque area. The main application used in this research was World Tool Kit, which is an API for developing Virtual Reality applications .

Alkadi [2] developed a mechanism to produce a comprehensive explanatory map of the heritage monuments in the city of Medina since the start of Islam. The study was conducted in several stages that include both tracking and recording of the locations and characteristics of each heritage monument on a modern digital GIS map. Eventually, a mobile application was developed where users could retrieve, analyze, and explore the stored data on the monuments to serve educational, cultural, scientific, and practical purpose. Takase et al. [3] used 4D-GIS to reconstruct the historic city of Kyoto covering the urban landscapes of Kyoto at different eras. They introduced a platform for Virtual Kyoto to integrate large collection of digital archives of arts and cultures of the city. Then, they created a database of all existing buildings and then developed VR models for these buildings.

The literature review revealed that there are number of studies which employed virtual and augmented reality techniques in the digital preservation of historical sites. However, and to the best of the researcher's knowledge, no previous research is done on the digital documentation of interior design features of the houses located in the Holy City of Makkah. This paper addresses this gap and contributes to the knowledge of digital preservation of the interior Islamic architectural elements in the historical houses of Makkah. 


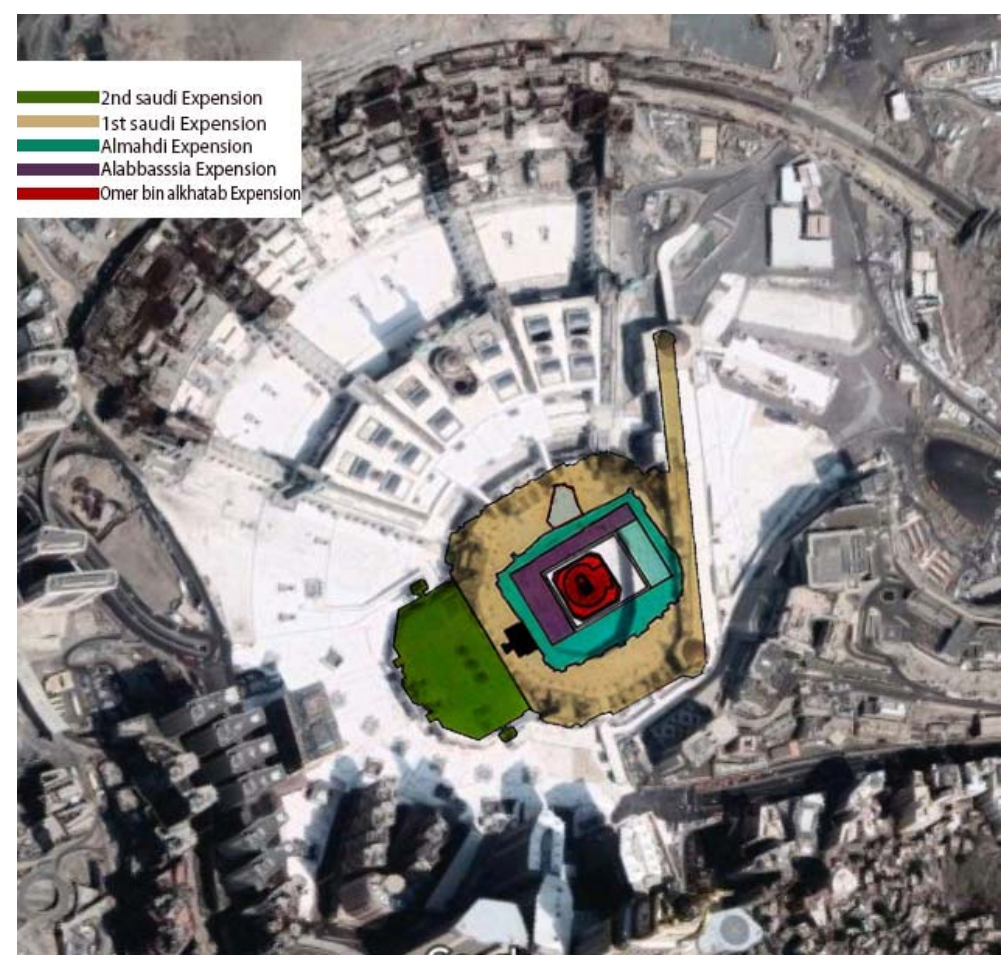

Figure 1: The historical expansion of the Holy Mosque [6].

\section{THE EXPANSION OF THE TWO HOLY MOSQUES AND ITS IMPACT ON THE SURROUNDING BUILDINGS}

The expansion of the area of the two Holy Mosques is not a new development. As the number of Muslims increased over the centuries, Muslim rulers have been aware of the importance of serving pilgrims and Umra performers and providing them with suitable housing and accommodation arrangements around the Holy Mosques for specific periods of time. This negatively affected the historical buildings in those areas, hence preserving them becomes more difficult to achieve. These expansion projects have begun since the era of the Muslim Khalifa, Omar ibn al-Khattab. Since then, these expansions have increased until the area cleared reached 29,100 square meters to 136,650 in the era of King Fahd as showing in Fig. 1 [4].Serving pilgrims and Umra performers who visit the Holy Mosques has even become a focus of the 2030 Saudi Vision as the importance of facilitating the hosting of more pilgrims (30 million pilgrims annually) has been set as an indicator in this vision [5].

In view of the surrounding areas of the Haram before the recent expansion, the researchers find that it included eight neighborhoods of historic Makkah, namely Shamiya, Al-Qarara, Shubayka, Al-Falaq, Sulaymaniyah, Al Raqubah, Almuda'a, and part of Al-Bab district). These areas include part of the historic architecture of thirteenth-century Makkah and the historic urban fabric of this city.

The expansions of the Holy Mosque were expanded to a depth of 380 meters after Bab alUmrah Street, during which approximately 1050 buildings were removed within the first six months. In order to implement this project, buildings of architectural and historical value as well as natural environmental zones that have a historical relation were identified. Then, the 
team of OMRANIYOUN documented the building technique and architectural details in traditional architecture. Moreover, a database storing all architectural details for the buildings was created. Figs 3 and 4 show the stages of documentation, which began with the region's photographic documentation and the use of GIS techniques, then identifying the buildings with historical value, numbering, then photographing them from the inside and outside. Also, the most significant architectural and decorative details were recorded for each building separately [8].

Total pilgrims in Ten years $1429 \mathrm{H}-1438 \mathrm{H}$

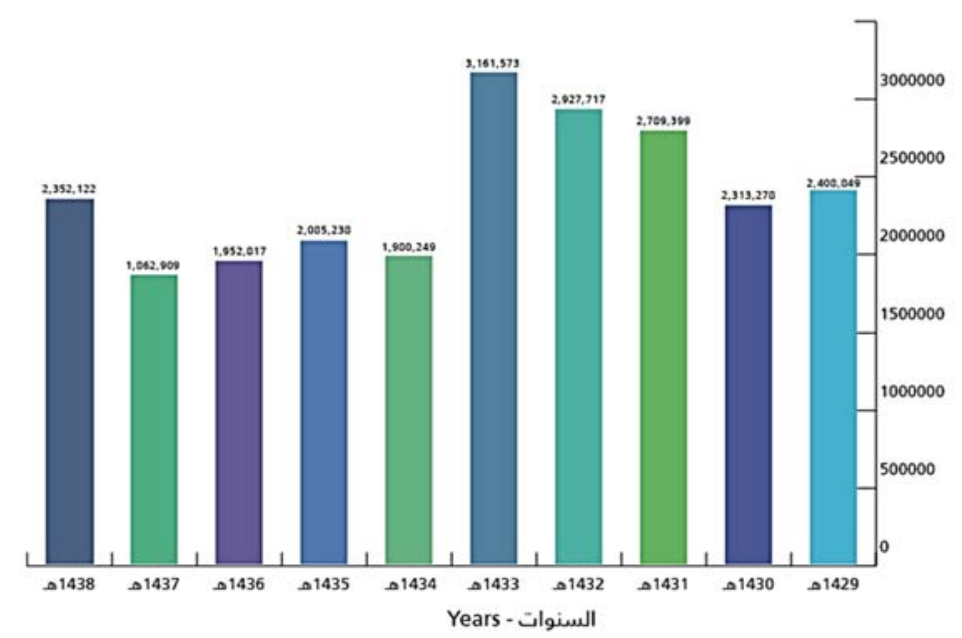

Figure 2: The total number of pilgrims in ten years from 2008 (1429H) to $2017(1438 \mathrm{H})[7]$.

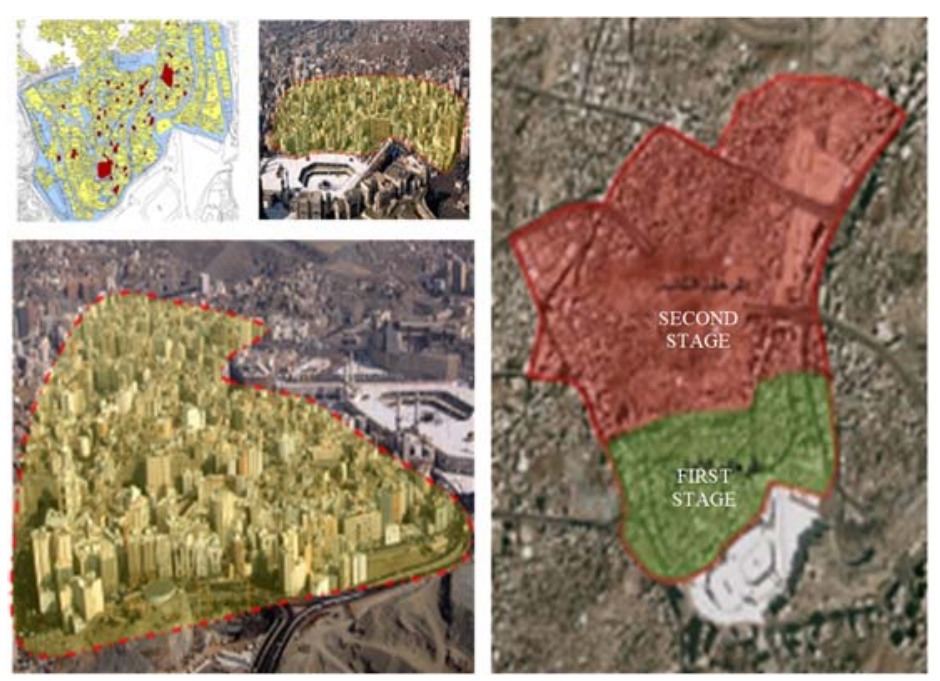

Figure 3: Aerial view for the historical expansion of the Holy Mosque [8]. 


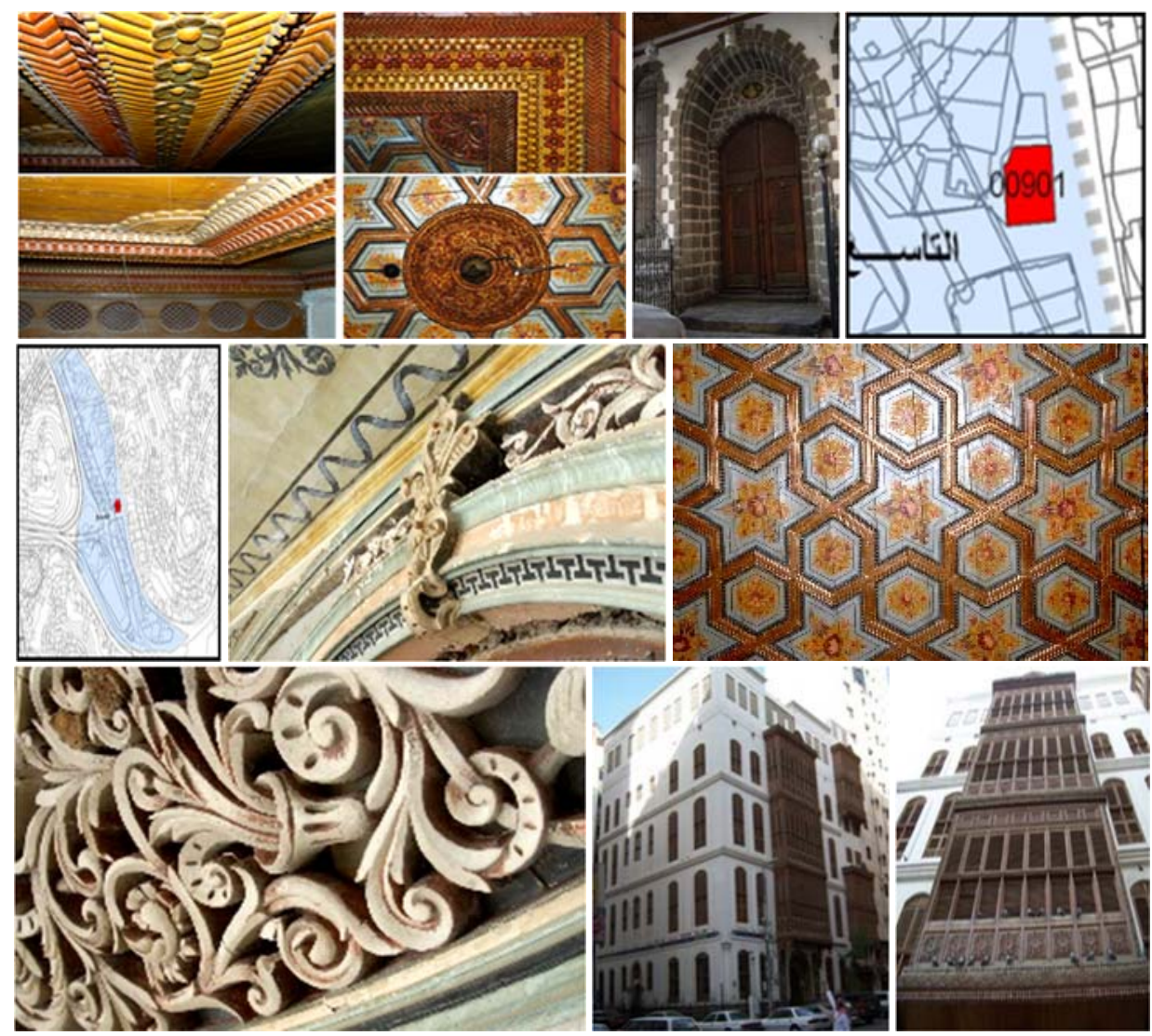

Figure 4: Samples of the Documented Architectural Elements (wooden and plaster artworks) [8].

\section{ARCHITECTURAL DOCUMENTATION OF HISTORICAL BUILDINGS}

The process of architectural documentation is one of the oldest methods of scientific research. It is one of the earliest scientific theories that focus on the events of the past and its interpretation and try to understand the present in the light of past events and developments. It is a process of recording facts and information by describing or drawing each element of the archaeological site.

A heritage site can be defined as a site that has lived with some sort of civilization for 100 years or more, and it has a historical value. It can also be defined as a site that gives a sense of grandeur and makes us want to know the culture that created its creativity for its aesthetic, historical, political or symbolic values [9].

The methods of architectural documentation for archeological sites vary according to different available techniques at the documentation era, as well as to the archaeological site and its historical value. All methods rely mainly on registration, classification, photography, and surveying documentation. The following two methods are used in the architectural documentation throughout the project. 
The first is the traditional method that relies on the manual effort and individual capabilities of man, which are done by manual and traditional measuring tools. The traditional methods of documenting the landscape and heritage environments, both architectural and urban methods have demonstrated accuracy and flexibility as a means of handling and documenting data. This method is available without the complexity of technology and limited costs compared to high-sensitivity and technical devices [10]. Samples of the traditional methods are photographs and artist interpretations, which portray life inside the buildings based on what books and verbal folklore have described. Some level of imagination and artistic freedom is used in this method. In this research, these artistic works were used as a reference when implementing the modern methods.

The second is the modern method that depends on electronic documentation, which is the subject of the current research.

\subsection{Traditional methods}

There are many traditional methods; the most important being photography and paintings of contemporary artists. This section will briefly discuss them.

\subsubsection{Technical drawings}

The oldest depiction of the Holy Mosque dates to the 11th century. It was discovered on a marble tablet currently in the Baghdad Museum showing some architectural details of the contracts and some important architectural elements in the Grand Mosque. Other depictions have been discovered since then, one of which is a painting of the Holy Mosque dating back to the fifteenth century in the British Museum [11]. Traditional documentation plays a significant role in understanding and critiquing architecture and assist contemporary painters in creating many expressive paintings that helped the authors in this research to visualize life inside the buildings. Among the artists we relied on were Dia Aziz Dia, Safia bin Zaqr and Najat Mutahar.

\subsubsection{Photography}

The art of photography reached Makkah in 1883 [11]. Many of the photographs have detailed the developments and expansions of the Haram area. Some of them showed pictures of the historical dwellings surrounding them. There are also many very rare and personal pictures depicting the daily life of Makkah and very few of them inside the buildings, some architectural details of the building were shown in these photographs.

\subsection{Modern methods of documenting and recording heritage data}

There are different ways of documenting and recording heritage data, including image-based modeling techniques, Virtual Reality, Photogrammetry, Remote Sensing, Global Positioning System (GPS) and Information Systems (GIS) amongst others [9]. The focus of this research will be on three techniques: Image-Based Modelling Techniques, AR and VR.

\subsubsection{Image-based modelling techniques}

Photographs and paintings can be used as an important reference for 3D visualization using architectural and technical software. These references help students and researchers visualize life within these buildings and navigate them using various techniques such as VR [12]. 


\subsubsection{Definition of VR}

Virtual reality is defined as a $3 \mathrm{D}$ interactive environment designed by computer programs that surrounds the reality of the user and introduces it into a virtual world so that the world appears to be realistic. Virtual reality may be fictional or an embodiment of reality. Interacting with VR occurs between the virtual environment and the user's senses and responses.

\subsection{Potential of VR}

Virtual architecture enables the individual to participate in the design of the building through his internalization of vision in virtual reality. This fulfills one of the social needs, in addition to predicting the final form of the output of construction and the possibility of movement within its interior spaces to ensure the effectiveness of the building in achieving the required function inside.

The digital space becomes part of one's imaginary reality, which allows for the construction of various three-dimensional formulations that are subject to time and movement. The virtual reality experience then allows the user to imaginatively inhabit and walk through the digital space and interacts actively with it. The application of VR assists both students and researchers in visualizing architectural designs for various purposes [12].

Guidi [13] explained in his paper the role of VR in many areas including science and technology. It is used in engineering, medicine, design, and art. It is one of the most appealing tools to present and expose an idea. VR and AR are the tools by which a user can experience different environment while he or she is at home. VR/AR use high tech computer system with advanced hardware and software to provide the user with believable environments. These virtual environments are used for training such as the flight simulators, education, and entertainment. They can also be used for many customized purposes such as medicine, raising awareness and others. If we look at architecture and design, the need of the virtual environments in this area can be easily seen. Car design and manufacturing for instance is one of the early adoption for VR and manufacturers use VR to help engineers and designers work together in a virtual world and come to an agreement for the final design.

\section{PILOT PROJECT}

Because the area around the Holy Mosque, which is relevant in this research, has been completely removed as mentioned in the first section, the current research project aims to highlight the importance of reviving these buildings in a virtual world and tries to simulate the golden period of architecture in the Haram area, we conducted an in-depth study and consulted existing archived references (visual and textual) which interested people have collected during the ages. To achieve the objectives of this research, we used a historic palace in Makkah (Palace of Ben Sulaiman) to create a model of historical buildings in that era.

\subsection{Description of the building}

Built in 1935, the palace consists of three main buildings in the south, middle and north, as well as an annex to the southern side of the building. The building is surrounded by several squares on the western and the eastern sides.

Due to the topographical nature of the building, the designer has taken an advantage of the natural elements in the way he designed the building which shows in the gradual distribution of spaces in the different floors; in addition to how that nature is reflected in the external design. 
The palace is owned by His Excellency Sheikh Hamad Al-Sulaiman, Minister of State in the early days of the Saudi era, and because of his career status, the palace buildings came to suit his functional needs. There is an apartment for the Sheikh's family in the northern building. The Middle building was a location for hospitality, parties and meals for important guests. The front part of southern building was for the official receptions of visitors and the back of it for the guards and staff. The Annex seems to have been allocated as a public service where there is a pump room in South-west corner of the Annex, and in the center, there is an Iwan across the open courtyard of the Annex [14] .

\subsection{Architectural character of the palace}

In general, the character of the traditional architecture of Makkah shows in this building demonstrated using wooden beams, and Rawashin and windows that are finished with circular or straight frames of different sizes and types depending on the function they serve.

Some notable features include is the way the roof is the most prominent section of the southern building, or the heavy use of decoration in the northern building, as well as the use of colored bricks with alcoves and surfaces, and the configurations of chimneys and cylindrical windows of bathrooms and kitchens on the upper surfaces.

In addition, iron was used in the lower floors and in the open sections of the Rawashin and windows for security reasons. The building is rich in gypsum ornaments and decorations, roof tiles, doors, windows and the internal ceilings. Paintings and drawings were seen on the walls of some reception rooms, bedrooms, and domes in the bathrooms.

The building is a distinct architectural masterpiece that reflects part of the architectural heritage of Makkah in the middle of the fourteenth century AH.

\subsection{Implementation}

The pilot has gone through several phases illustrated in Fig. 5. The stages have been broken down in Fig. 5.

\subsubsection{Field visit phase of the building}

The purpose of this visit was to document the building using photographs and other recording equipment to show the important architectural details and categorize the information for the next stage. The following tools have been used:

1. Laser 3-D scanners for elevations, plans, and 3-D modelling.

2. Drones for the aerial photography.

3. Land survey regular's equipment.

4. Video filming cameras.

5. DSLR cameras and 360 cameras to capture the spherical panoramas for the virtual tour.

A spherical panorama captures not only $360^{\circ}$ view perpendicular to the camera lens, but also the floor and ceiling of the building being documented. This feature was crucial for the

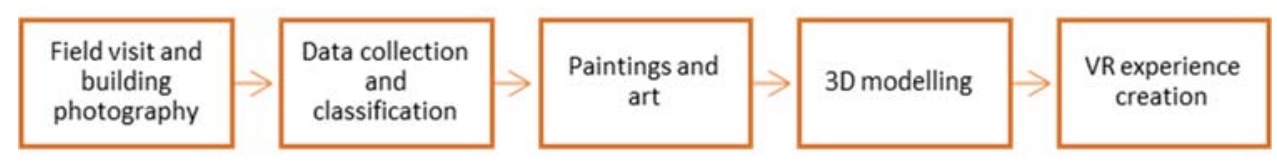

Figure 5: The stages of documentation. 
images taken inside the buildings so that we could document and understand the structural system of the interior. This camera choice was based on the camera's capacity to automatically stitch the panoramas together which expedited the process. The virtual tour environment was created using Kolor Pano tour Pro. This software enabled us to stitch together adjacent panoramas, so a user can virtually walk around the building.

\subsubsection{Results of data collection and classification}

Based on the field visit, some of the spaces in the building were identified and classified according to our needs and the collection and adaptation of information in such a way that we can easily understand and present it in a historical, academic, scientific, engineering and professional manner.

5.3.3 Utilizing paintings and plaster arts to recreate elements of interior design Inspired by life in this historical period, and with the aim of creating a VR experience of that period, we consulted the works of the most prominent artists who drew and visualized life in that era, like Aziz Dia, Safia bin Zaqr, and Najat Mutahar. Many plastic paintings have been used in the three-dimensional models we created.

\subsubsection{D Model creation}

To create a realistic representation of that historical period, a model was designed using software, Auto-cad 2017-3D max 2017.

\subsubsection{Virtual reality multimedia}

Finally, the virtual tour was turned into an animated multimedia using the Panotour Pro (Kolor) software environment and tools. It appears in the form of an animation directly viewable as Adobe Flash in a web environment.

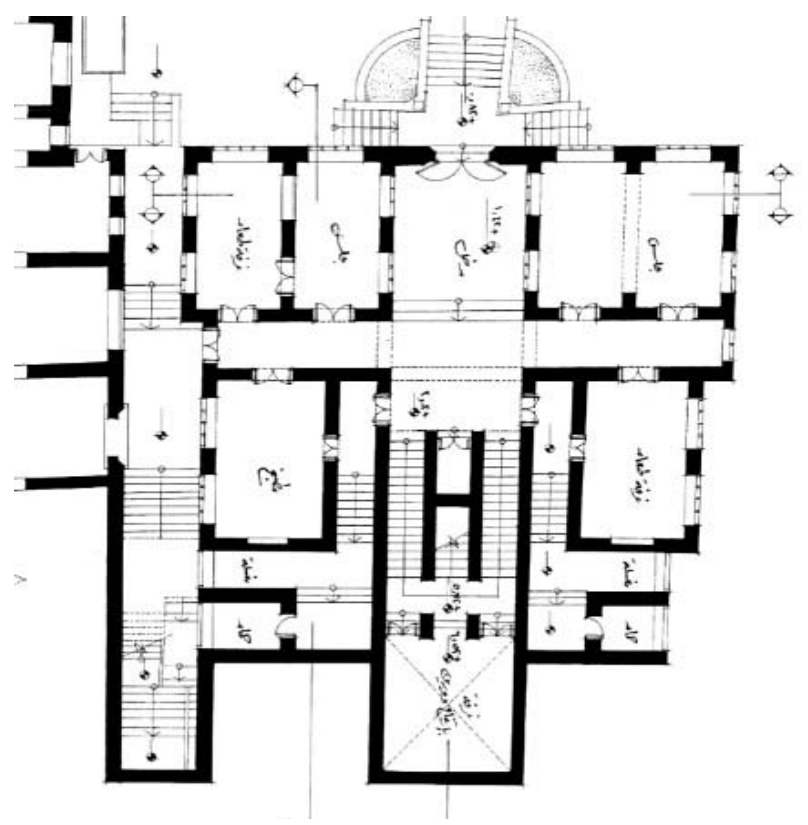

Figure 6: Palace plan [14]. 

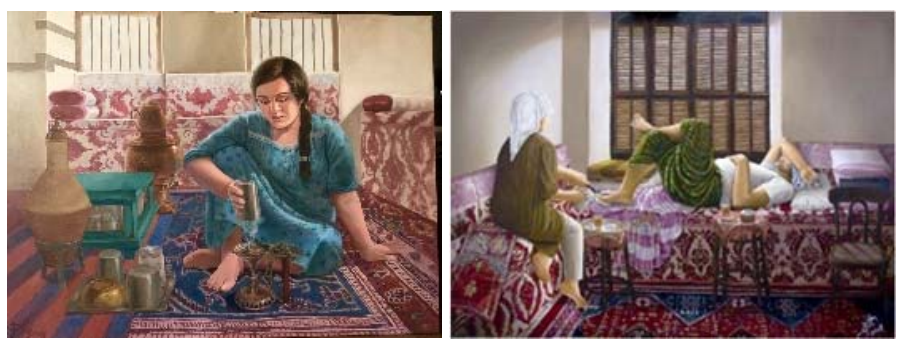

Figure 7: Painting [15].

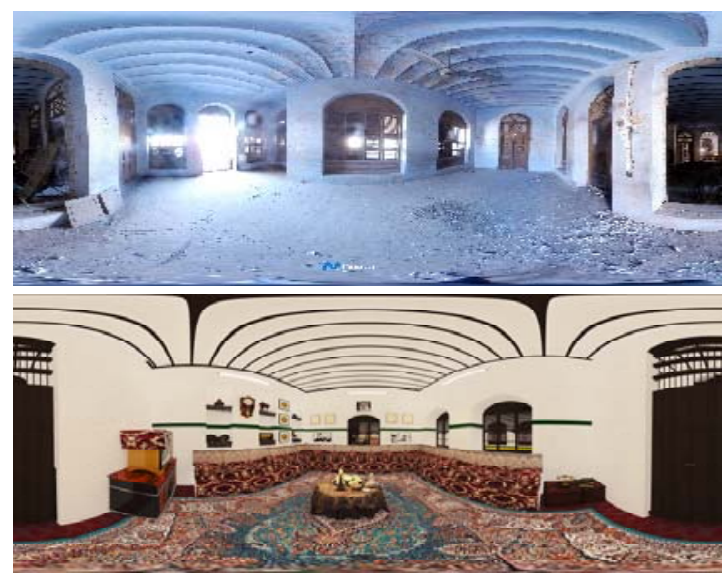

Figure 8: Interior space for the Palace of Ben Suleiman taken using DSLR cameras and 360 cameras (above) and 3D modelling (below).

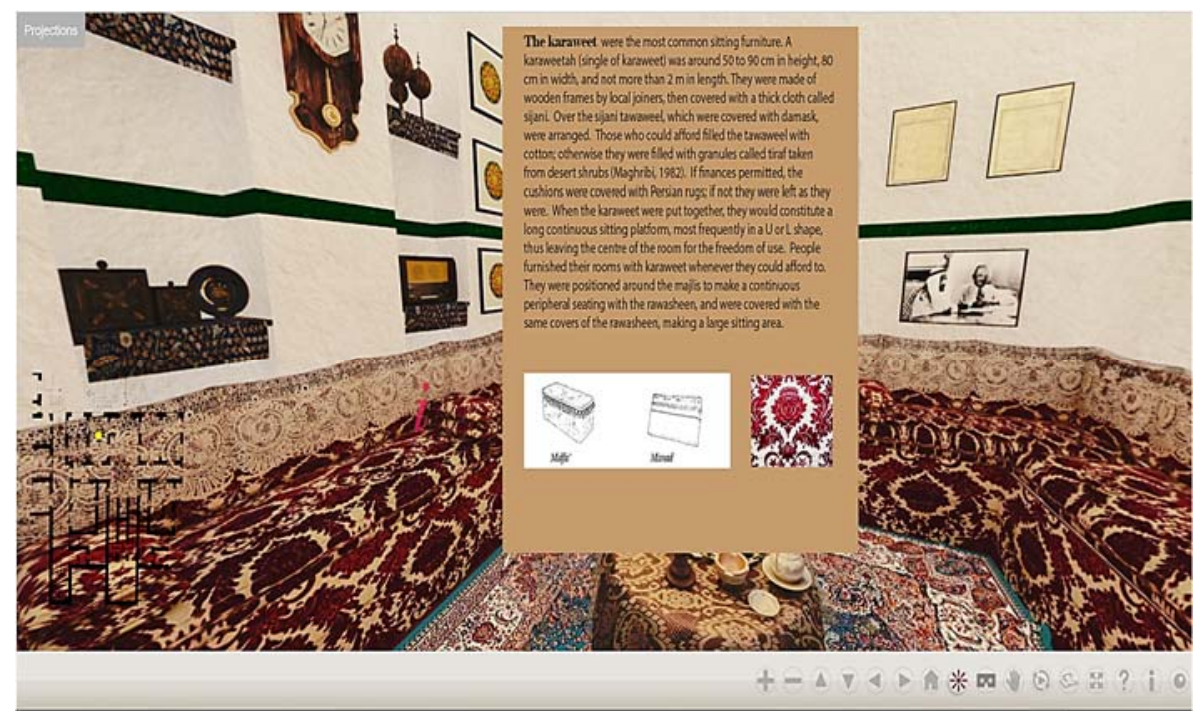

Figure 9: Screenshot of the suggested virtual reality tour [16]. 


\section{CONCLUSIONS}

In this paper, the researchers piloted the implementation of VR multimedia tour of a historical building in the Haram area, which went through five steps (filed visit, data collection and classification, utilizing artistic representations, 3D model creation, and multimedia tour creation). Our focus was on creating a rich and interactive VR experience that is further enriched with detailed historic information on the architecture and decorations.

The experimentation with immersive digital media creation and thinking of various ways of how this technology can enrich research in the field of architectural documentation and heritage preservation, had led us to further consider the potential of this technology for national projects of the same type, as well as their academic and research value in other areas.

Though we do not ignore the high cost of implementing VR multimedia in such projects, we still like to highlight the aesthetic and learning qualities of such digital and interactive experiences. Possible ways to enhance the outcomes of this study are: 1) Conducting in-depth studies of the architectural heritage of historic areas and buildings in Makkah to add more details to the informational databases created for this study; 2) creating more immersive models that rely on video and motion rather than on still photos; and 3) developing VR experiences based on these interactive models that can be viewed using VR headsets. We recommend that the modern framework of architectural documentation used in this study be enhanced and used with other historical buildings in the Haram area to document their internal and external peculiarities and heritage.

\section{ACKNOWLEDGEMENTS}

We would like to thank OMRANIYOUN, Holy Makkah Municipality, Umm Al Qura University, Development of Makkah Region Authority, the custodian of the two Holy Mosques institute hajj and Umrah research, for their effort in documenting the haram area. Many thanks go also to collage of Islamic architecture students at Umm Al Qura University for providing information and maps of bin Suliman palace which were very helpful for this paper. Finally, we would like to thank the artist Najat Mutahar for sharing her painting of the daily life in Hijaz with us.

\section{REFERENCES}

[1] Gaafer, A., Use OF "photo-modelling techniques" in 3D documentation of Islamic architecture heritage sites in occupied Jerusalem (Al-Quds City). Shoubra's Engineering Research Magazine, Shoubra, p. 11, 2005.

[2] Alkadi, A.A., Proposed mechanism for the use of historical maps to track and record heritage monuments on modern digital maps using informatics techniques: Medina case study. University of Dammam Scientific Journal, Dammam, p. 155, 2011.

[3] Takase, Y. et al., Virtual Kyoto: visualization of historical city with 4D - GIS, virtual reality and web technologies. Int Arch Photogram Remote Sens Spat Inf Sci., p. 975, 2008.

[4] Magraby, M. \& Alhijaz, A., Jeddah: Dar AlElm, pp. 24-32, 1984.

[5] Government of Saudi Arabia, Saudi Arabia Vision 2030, 2016.

[6] Google maps, Online. https://www.google.co.uk/maps.

[7] General Authority for Statistics, Hajj Statistics, p. 10, 2017.

[8] Fatani, M., Documentation of Alshamiya Region in the Alharam Piazza's Approved Expansion - Second Stage ppt, 2011.

[9] Gaafr, A. \& Namara, N., Modern Methods in the Architectural Documentation of Archaeological Sites in Palestin, p. 3. 
[10] Rashed, A., A Study of Alrmaila Fort in AlAin Sustainability if Heritage Environments: Documentation of Interial Architecture as an Entry to the Conservation Process. Proceedings of the Third Conference for National Architectural Heritage, AL Madinah, p. 3, 2013.

[11] Mirza, M. \& Shawish, A., The Illustrated Atlas of Makkah ALMukarramah and the Holy Regions, King Abdulaziz Foundation for Research and Archives, pp. 54-55, 2004.

[12] Santagati, C., Inzerillo, L. \& Di Paola, F., Image-based modelling techniques for architectural heritage 3D digitalization: limits and potentialities. ISPRS - Int Arch Photogram Remote Sens Spat Inf Sci, Online, 2013.

[13] Guidi, G., Russo, M. \& Angheleddu, D., Digital reconstruction of an archaeological site based on the integration of 3D data and historical sources. International Archives of the Photogrammetry, Remote Sensing and Spatial Information Sciences, 2013.

[14] Surveying and Documentation of Alsulaiman's Palace at Jarwal, Um Alqura University Summer Training Team, College of Islamic architecture: Makkah, 2010.

[15] Mutahar, N., We Were Like That (painting collection), 2013.

[16] Akbar, S., Home and Furniture: Use and Meaning of Domestic Space, Jeddah, Saudi Arabia. University of Newcastle-upon-Tyne, p. 91, 1998. 